\title{
Usefulness of PRP Therapy in Androgenic Alopecia
}

\author{
Zahed Parvez, Samina Akter, and Afia Tahsin Shobnom
}

\section{ABSTRACT}

\begin{abstract}
Alopecia means loss of hair. Primarily there are two types of alopecia. Noncicatricial alopecia and Cicatricial alopecia. Androgenic alopecia is non cicatricial localized alopecia and displays relatively high rates of occurrence in both men and women. Injections of platelet-rich plasma (PRP) have shown to be a successful regenerative treatment for androgenic alopecia. It is a well-tolerated procedure and easy to perform. The objective clinical results are good. It is safe and non-allergenic. In our institution, more than 300 patients were given PRP and their terminal hair mass, hair texture, anagen/telogen hair ratio, keratinocyte proliferation, blood vessel density, and other factors were assessed. More than 85 percent of patients who underwent PRP treatment, had a very positive outcome.
\end{abstract}

Keywords: Androgenic Alopecia, Platelet-rich plasma, Regenerative.
Submitted : May 28, 2021

Published : June 20, 2021

ISSN: 2593-8339

DOI: 10.24018 /ejmed.2021.3.3.897

\section{Dr. Zahed Parvez}

MBBS (DU), BCS (Health), MPH (BSMMU), DDV (DU),

Trained in Cosmetic \& Hair Transplant Surgery (India), Consultant \& Cosmetic Surgeon,

Assistant Professor, Shaheed Suhrawardy Medical College Hospital, Dhaka, Bangladesh.

(e-mail: zahedparvezmmc@ gmail.com) Dr. Samina Akter*

Medical Officer, Dr. Zahed's Hair \& Skinic, Panthapath, Dhaka, Bangladesh.

(e-mail: samina.mithila123@gmail.com) Dr. Afia Tahsin Shobnom

Medical Officer, Dr. Zahed's Hair \& Skinic, Panthapath, Dhaka, Bangladesh.

(e-mail: drgmprincedmc ${ }^{\circledR}$ gmail.com)

*Corresponding Author

\section{INTRODUCTION}

Fifty percent of men will experience some degree of AGA, also known as male-pattern baldness or MPHL, by age 50, and nearly 50 percent of women will experience AGA (female-pattern hair loss, FPHL) over the course of her lifetime [1]. Given the prevalence of hair loss in these populations, targeted therapies that reduce the appearance of thinning by delaying, arresting, or reversing the underlying pathology are highly desirable. Topical Minoxidil and oral finasteride are the only FDA-approved treatments for androgenic alopecia (AGA) [1]. Platelet-rich plasma (PRP) is gaining popularity as a treatment option for androgenic alopecia because of its rapid response.

\section{METHODS}

Between 2019 and 2020, all patients with androgenic alopecia who had failed to advance on topical Minoxidil and finasteride were considered for PRP treatment. Among them we select 55 patients to study. HBSAg and platelet count were measured. Hematological diseases, thyroid dysfunction, malnutrition, and other dermatological disorders that cause hair loss were all ruled out. The hair pull procedure was done two times by the same clinician before each session. From the base close to the scalp, a packet of 50-60 hair was gripped between the thumb, index, and middle finger. Per session, the hair was forcefully tugged away from the scalp, and the removed hair was counted.

\begin{tabular}{cc} 
TABLE I: SUMMARY OF THE CASES & \\
\hline Total number of patients & 55 \\
Male & 40 \\
Female & 15 \\
No of PRPs taken & 8 \\
Time required to have a satisfactory result & $7-8$ months \\
\hline
\end{tabular}

\section{REsUlts}

All of our patients (100\%) had a positive hair pull test with a mean number of ten hairs prior to therapy. The pull test was negative in 9 patients $(81.81 \%)$ after the sixth session, for an average number of three hairs. Patients found a substantial decrease in hair loss between the fifth and sixth dose. Patient satisfaction was good overall. 


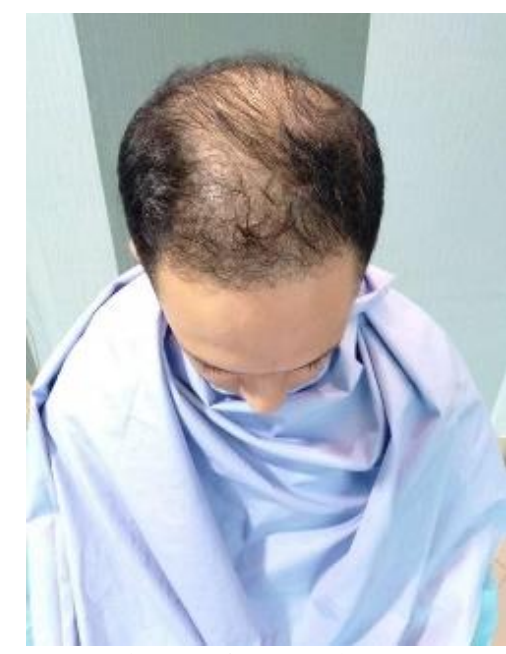

Fig. 1. Before PRP therapy.

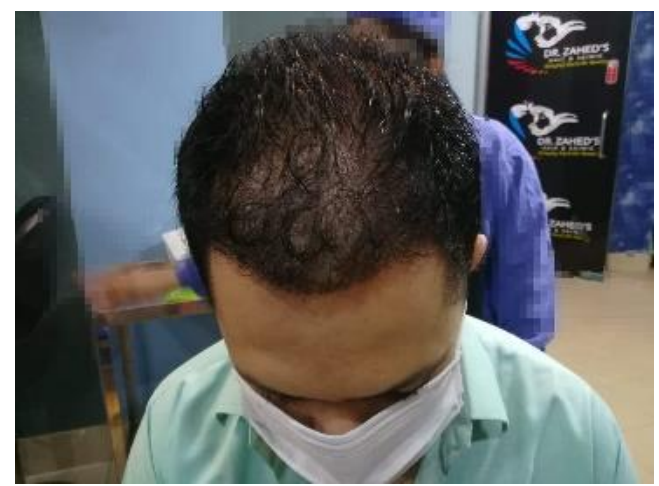

Fig. 2. After 8 sessions of PRP therapy.

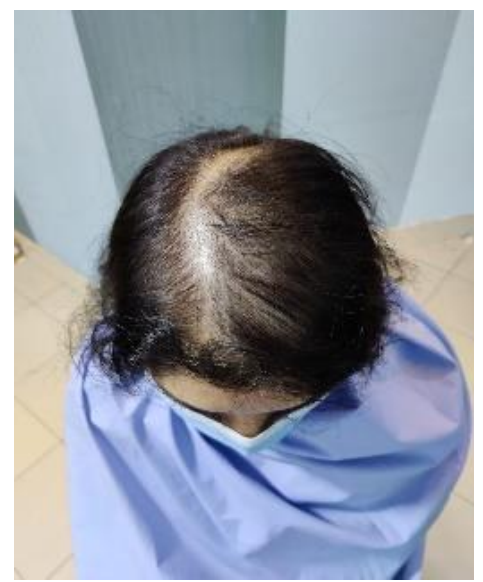

Fig. 3. Before PRP therapy.

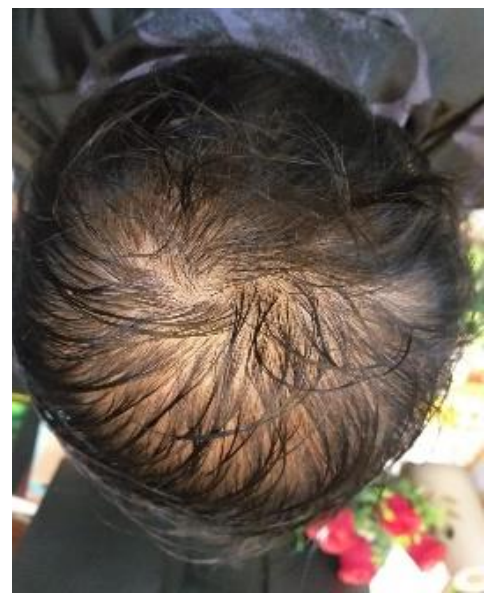

Fig. 4. After 6 sessions of PRP therapy.

\section{DISCUSSION}

Hair loss is linked to poor self-esteem which causes depression and has a direct impact on psychological disorder. The only FDA-approved treatments for androgenic alopecia are topical Minoxidil and oral finasteride, which can be used alone or in conjunction [1]. Minoxidil, on the other hand, has a number of confirmed side effects, including headache and a rise in other body hairs while oral finasteride has been linked to libido loss [2]. Finasteride interferes with a male fetus's genital growth and is thus should not be used in pregnant women and others who are planning to become pregnant [3].

The most prevalent form of baldness is androgenic alopecia, which is marked by gradual hair loss. Caucasians have the highest prevalence, with up to $80 \%$ of Caucasian men and $40 \%$ of Caucasian women affected. AGA was found to be prevalent in 58 percent of population aged 30-50 years in a survey [4]. Even though it may begin at puberty, the occurrence of AGA rises with age [5].

We prepared PRP by single spin method, in which blood cell layers were manually separated. Activation of platelets through coagulation triggers the secretion of various growth factors, which produce mitogenic effects in various cell types. Activated PRP promotes the proliferation of dermal papillary cells and prevents their apoptosis.

Because of its possible role of skin rejuvenating benefits, accelerated healing, reduced inflammation, and decreased risk of hypertrophic keloids and scars, PRP has also drawn interest in cosmetic surgery, orthopedic surgery, and cardiac surgery [6]. Platelet rich plasma contains platelet derived growth factor (PDGF), TGF-beta 1, vascular endothelial growth factor (VFGF), epidermal growth factor (EGF), insulin like growth factor (IGF), fibrinogen (Fg), fibronectin (Fn) and thrombospondin-1 (TSP-1) [7]. These growth factors are believed to stimulate hair and stem cell proliferation and trans-differentiation, as well as the formation of new follicular units. Growth factors also play a part in hair shaft elongation. [8]

After eight PRP sessions, the hair pull test turned negative in our study and moderate improvement in hair volume and coverage was observed.

\section{CONCLUSION}

There are certain drawbacks to our research. The findings of a trichoscopic hair test should have been more realistic. The sample size is very limited. The average patient followup is therefore insufficient to draw conclusions about longterm efficacy. As a result, further research with a longer follow-up period is needed.

\section{REFERENCES}

[1] Olsen EA, Weiner MS, Delong ER, Pinnell SR. Topical minoxidil in male pattern baldness. J Am Acad Dermatol. 1985; 13: 185-92. [PubMed] [Google Scholar].

[2] Kaufman KD, Olsen EA, Whiting D, Savin R, DeVillez R, Bergfeld $\mathrm{W}$, et al. Finasteride in the treatment of androgenic alopecia. J Am Acad of Dermatol. 1998; 39: 578-89. [PubMed] [Google Scholar].

[3] Messenger AG. Medical management of male pattern hair loss. Int $\mathbf{J}$ Dermatol. 2000; 39: 585-6. [PubMed] [Google Scholar].

[4] Gardner MJ, Demetrakopolous D, Klepchick PR, Mooar PA. The efficacy of autologous platelet gel in pain control and blood loss in total knee arthroplasty. An analysis of the haemoglobin, narcotic 
requirement and range of motion. Int Orthop. 2007; 31: 309-13. [PMC free article] [PubMed] [Google Scholar].

[5] Glover JL, Weingarten MS, Buchbinder DS, Poucher RL, Deitrick GA, 3rd, Fylling CP. A 4-year outcome based retrospective study of wound healing and limb salvage in patients with chronic wounds. Adv Wound Care. 1997; 10: 33-8. [PubMed] [Google Scholar].

[6] Katsuoka K, Schell H, Wessel B, Hornstein OP. Effects of epidermal growth factor, fibroblast growth factor, minoxidil and hydrocortisone on growth kinetics in human hair bulb papilla cells and root sheath fibroblasts cultured in vitro. Arch Dermatol Res. 1987; 279: 247-50. [PubMed] [Google Scholar].

[7] Besti EE, Germain E, Kalbermatten DF, Tremp M, Emmenegger V. Platelet-rich plasma injection is effective and safe for the treatment of alopecia. Eur J Plast Surg. 2013; 36: 407-12. [Google Scholar].

[8] Kaliyadan F, Nambiar A, Vijayaraghavan S. Androgenetic alopecia: An update. Indian J Dermatol Venereol Leprol 2013; 79: 613-25. 10.4103/0378-6323.116730 [PubMed] [CrossRef] [Google Scholar].

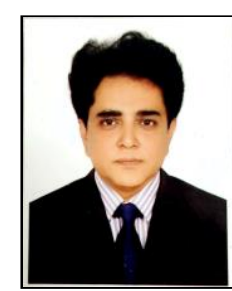

Dr. Zahed Parvez is a renowned Professor of Shaheed Suhrawardy Medical College Hospital, Dhaka, Bangladesh. He is the pioneer of Hair Transplantation Surgery in Bangladesh. $\mathrm{He}$ completed his MBBS degree from Mymensingh Medical College, Bangladesh. He is practicing dermatology since 2003.

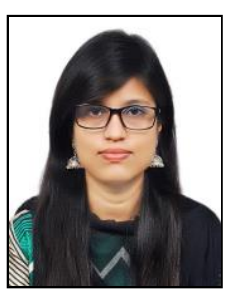

Dr. Samina Akter is currently working as a Medical Officer at Dr. Zahed's Hair \& Skinic, Panthapath, Dhaka, Bangladesh. Her research focus is in the area of public health, contagious diseases, etc. She holds an MBBS degree from Kumudini Women's Medical College, Tangail, Bangladesh.

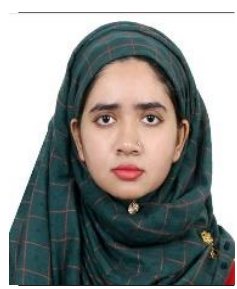

Dr. Afia Tahsin Shobnom is currently working as a Medical Officer at Dr. Zahed's Hair \& Skinic, Panthapath, Dhaka, Bangladesh. Her research focus is in the area of Dermatology. She holds an MBBS degree from Shaheed Suhrawardy Medical College, Dhaka, Bangladesh 